\title{
Multiple Sklerozlu Hastada Spastisite ile Karışabilecek Femur Başı Avasküler Nekrozu: Olgu Sunumu
}

\author{
Avascular Necrosis of Femoral Head Which Maybe Confused with Multiple Sclerosis \\ Spasticity in a Multiple Sclerosis Patient: Case Report
}

\author{
Fatih Baygutalp, Işılay Işık*, Kazım Şenel** \\ Özel Buhara Hastanesi, Fiziksel Tıp ve Rehabilitasyon Kliniği, Erzurum, Türkiye \\ *Özel Buhara Hastanesi, Radyoloji Kliniği, Erzurum, Türkiye \\ **Atatürk Üniversitesi Tıp Fakültesi, Fiziksel Tıp ve Rehabilitasyon Anabilim Dalı, Erzurum, Türkiye
}

\section{Özet}

Multipl skleroz (MS) merkezi sinir sisteminin (MSS) kronik, inflamatuar, demiyelinizan bir hastalığıdır. Hastalık daha çok atak ve remisyonlarla seyreder. Lezyonlar MSS'inde bulundukları bölgelere göre çeşitli semptomlar verirler. Tedavi atak tedavisi, profilaktik tedavi ve semptomatik tedavi olarak üç bölüme ayrılabilir. Glukokortikoidler (GC) MS akut ataklarında çoğunlukla intravenöz pulse formunda yılda birkaç kez 3-10 gün arasında kullanımakta ve atakların gerilemesini hızlandırmaktadır. GC'nin kas-iskelet sisteminde çeşitli olumlu ve olumsuz etkileri vardır. Avasküler nekroz (osteonekroz) GC kullanımının sık görülen bir komplikasyonudur. GC kullanımına bağlı avasküler nekroz en sık femur başında görülür. MS'li hastalarda GC kullanımına bağlı femur başı avasküler nekrozu (FBAVN) oluşabilir. FBAVN asemptomatik ve ağrısız olabilir veya ağrı ile kalçalarda kısıtlılığa yol açabilir. MS'li hastalarda kalçada spastisiteden dolayı ağrı ve kısıtlıık olabileceğinden ayırıc tanıda mutlaka FBAVN göz önünde bulundurulmalı ve ekarte edilmelidir. Bu yazıda MS tanısı ile izlenmekte iken yılda birkaç kez yüksek doz GC kullanan hastada gelişen FBAVN olgusu sunulmuştur ve güncel literatür ışı̆̆ında bu iki hastalığın birlikteliği tartışılmıştır. Bu olgu sunumunun amacl; GC kullanma öyküsü olan MS hastalarında normal direkt radyografi bulguları olsa bile, magnetik rezonans görüntüleme (MRG) ile FBAVN'nin ekarte edilmesinin önemine dikkat çekmektir. FBAVN'nin klinik semptomları MS'in kalça tutulumu ile karışabildiğinden, FBAVN'nin atlanması veya geç tanı konulması özürlülüğü arttırabilir. (Türk Osteoporoz Dergisi 2014;20: 29-33)

Anahtar kelimeler: Multipl skleroz, spastisite, femur, glukokortikoidler, avasküler nekroz

\section{Summary}

Multiple sclerosis (MS) is a chronic, inflammatory, demyelinating disease of the central nervous system (CNS). Disease is often characterized by attacks and remissions. The lesions present various symptoms according to their locations in the CNS. The treatment can be divided into three categories as attack treatment, prophylactic therapy and symptomatic treatment. Glucocorticoids (GC) are used in acute attacks of MS usually in intravenous pulse form for 3-10 days several times in a year and they accelerate the remission of attacks. GC has various positive and negative effects on the musculoskeletal system. Avascular necrosis (osteonecrosis) is a common complication of GC using. GC-induced avascular necrosis is frequently seen in femoral head. GC-induced femoral head avascular necrosis (FHAVN) may occur in patients with MS. FHAVN may be asymptomatic and painless or may cause pain and limitations in the hips. Since hip pain and limitations can be seen in MS patients due to spasticity, FHAVN should be absolutely considered and ruled out in differential diagnosis. In this article, a FHAVN case developed due to high-dose GC using for several times a year in a patient while being followed-up for MS was presented, and the association of these two diseases was discussed in the light of current literature. The aim of this case report is to point out the importance of ruling FHAVN by magnetic resonance imaging (MRI) in MS patients even they have normal direct radiography findings. Ignoring or late diagnosing FBAVN may increase disability. Since clinical symptoms of FHAVN can be confused with MS's hip involvement, ignoring or late diagnosing FHAVN may increase diasability. (Turkish Journal of Osteoporosis 2014;20: 29-33)

Key words: Multiple sclerosis, spasticity, femur, glucocorticoids, avascular necrosis 


\section{Giriş}

Multipl skleroz (MS) atak ve remisyonlarla seyreden merkezi sinir sisteminin (MSS) kronik, inflamatuvar demiyelinizan bir hastalığıdır. Görme bozukluğu, duyu bozuklukları, ekstremitelerde ağrı, motor fonksiyon kaybı, denge bozukluğu, cinsel işlevlerde bozukluk, mesane ve barsak sfinkter bozukluğu gibi farklı nörolojik defisitlerle ortaya çıkabilir $(1,2)$. Motor semptomlar tipik olarak güçsüzlük ve spastisite şeklindedir $(3,4)$. Spastisiteye daha çok bacaklarda rastlanır ve ağır spastik parapareziye yol açar. Spastisiteye bağlı sertlik, kramp, spazm ve ağrı olur (5).

MS tedavisi atak tedavisi, profilaktik tedavi ve semptomatik tedavi olarak üçe ayrılabilir. Glukokortikoidler (GC) MS tedavisinde sadece ataklar sırasında kullanılır. GC'ler atağın kısa sürmesi ve tam olarak düzelmesi için yüksek doz ve 3-10 gün arasında kullanılmaktadır. Tedaviye yanıta veya atağın şiddetine göre bu tedavi izleyen haftalarda tekrarlanabilir. MS ataklarında yılda birkaç kez yüksek doz GC kullanıldığından avasküler nekroz (AVN) (osteonekroz) gelişebilir (6). GC kullanımı nontravmatik osteonekrozun en sık nedenidir. Hastalık en sık kalça eklemini etkilemektedir. AVN spesifik bir hastalık olmayıp femur başının kanlanmasını bozan farklı patolojik süreçlerin bir sonucudur. Sistemik, lokal ve hematolojik faktörler sebep olabilir. GC'ler embolizasyon, kemik iliği şişmesi, damar duvarı hasarı gibi patogenetik mekenizmalarla AVN oluşturur (7). FBAVN asemptomatik, ağrısız olabilir veya ağrı ile kalçalarda kısıtlılığa yol açabilir. GC kullanma öyküsü olan MS hastalarında kalça ağrısı olsun veya olmasın, direkt radyografi normal olsada FBAVN ekarte edilmelidir. MS hastalarında FBAVN'nin atlanması veya geç tanı konması özürlülüğü arttırabilir.

\section{Olgu}

Kırk dokuz yaşında kadın hasta 18 yıllık MS hastası, yürüyememe, 5 yıldır var olan sağ kalçada kısıtlıık ve ağrı şikayeti ile başvurdu. Sağ kalça ağrısının sürekli olduğunu bazen ani ağrı krizlerişseklinde ortaya çıktığını belirtti. Her yıl birkaç kez MS atağı geçirdiğini ve atak tedavilerinde yüksek doz GC kullanıldığı öğrenildi, ek hastalık öyküsü yoktu. Yapılan fizik muayenede; eklem hareket açıklığı; her iki kalçada tüm yönlerde çok kısıtlı ve sağ tarafta çok ağrılıydı. Adale testi; her iki alt ekstremite proksimal ve distalde 2/5, nörofizyolojik brunnstrom motor evre; alt ekstremite; evre 2, spastisite Modifiye Ashworth Skalasına (MAS) göre her iki kalça ve dizlerde grade 4, her iki ayak bileğinde grade 5, duyu muayenesi normal, yürüme analizi fonksiyonel ambulasyon sınıflamasına (FAS) göre; kategori 1-ambulatuvar idi. AP pelvis radyogramında (Resim 1) femur başında aseptik nekroz alanı seçilememekte olup femur başında subkondral kırık ya da kresent işareti izlenmemektedir. Olgunun MRG'de (manyetik rezonans görüntüleme) femur başında subkondral kemik yapıda T1 AG'lerde (Resim 2, 3) periferi hipointens santrali izointens, T2 AG'lerde periferi hiperintens santrali heterojen hipointens lezyon alanı izlendi. Lezyon seviyesinde femur başında subkondral kemikte çökme ve kıkırdakta düzensizlik (Resim 3,4) izlendi.

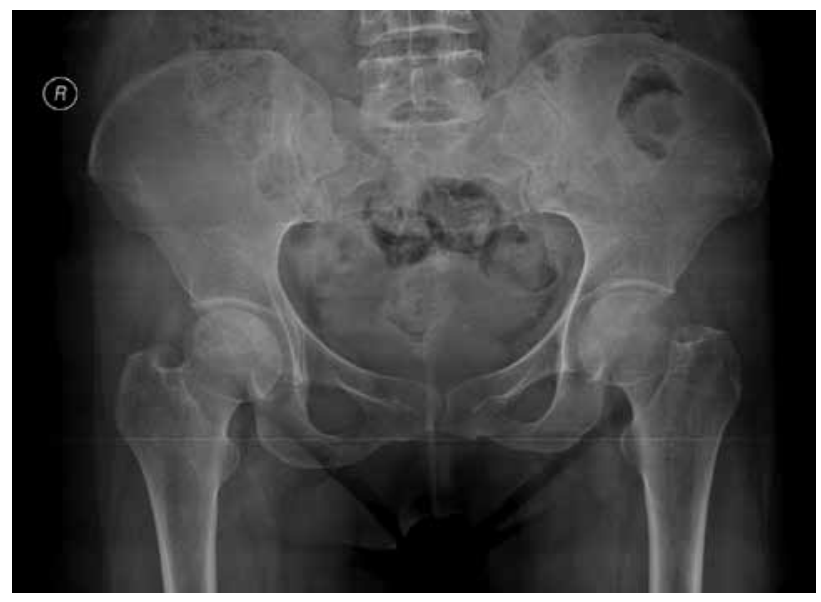

Resim 1. Direkt pelvis radyografi. Femur başı normal olup subkondral kırık ya da kresent işareti izlenmemektedir

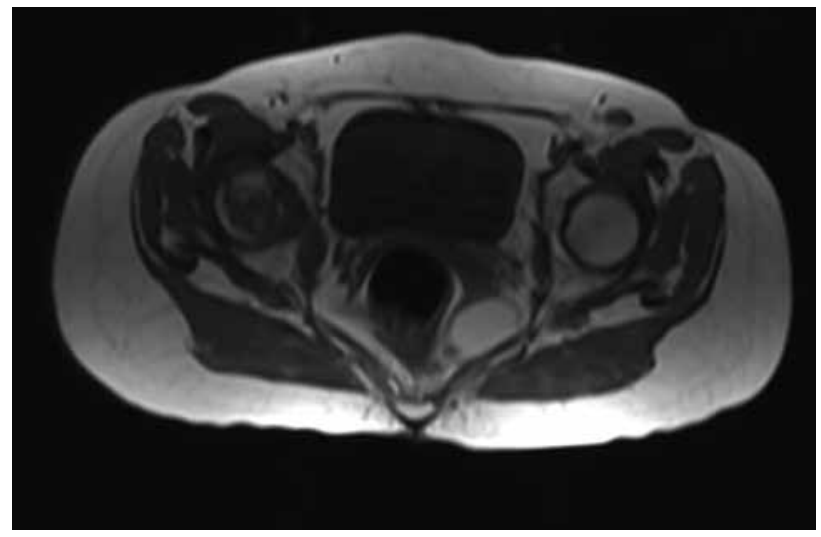

Resim 2. Aksiyel T1A MRG görüntüsü. Sağ femur başı subkondral kemik yapıda çökme, periferi hipointens santrali izointens aseptik nekroz alanı ve kresent bulgusu izlenmektedir

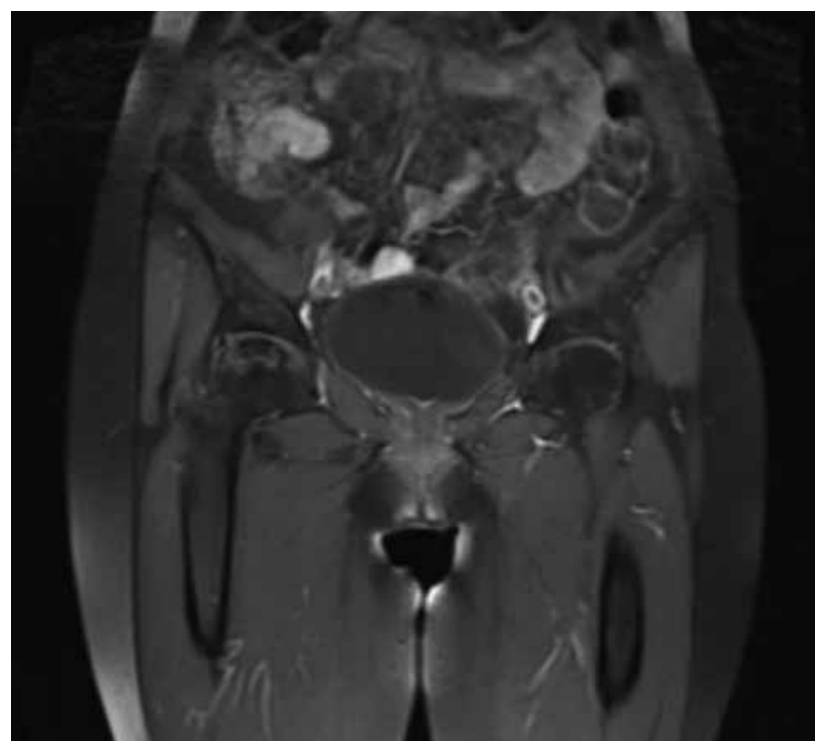

Resim 3. Koronal yağ baskılı T1A MRG görüntüsü. Sağ femur başı subkondral kemik yapıda çökme ve periferi hiperintens santrali hipointens aseptik nekroz alanı izlenmektedir 
Ayrıca femur baş ve boyun kesiminde kemik iliğinde yağ baskılı T2A görüntülerde (Resim 4) hafif hiperintensite ile karakterize kemik iliği ödemi ile uyumlu sinyal değişiklikleri izlendi. Mevcut bulgularla hastaya sağ tarafta FBAVN tanısı kondu. Modifiye Steinberg sınıflamasına göre evre 3 olarak kabul edildi. Tedavide ağrı için tramadol hcl + parasetamol tb, koltuk değneği, spastisite için her iki diz, kalça ve ayak bileğine soğuk paket verildi. Her iki alt ekstremitelere progresif dirençli kas güçlendirici egzersizler, germe egzersizleri, sağ kalçaya TENS, denge, yürüme ve koordinasyon eğitiminden oluşan fizik tedavi ve rehabilitasyon programı uygulandı. Uyguladığımı 30 seans tedavi sonucunda olgunun ağrı VAS'ı 8 cm'den 4 cm'ye geriledi. Kas gücü değişmedi, spastisite MAS'a göre her iki kalça ve dizlerde grade 3, her iki ayak bileğinde grade 4'e geriledi. Hasta semptomatik ve MRG'nin pozitif olduğu çökme öncesi dönemde olduğundan; kor dekompresyon ve damarlı veya damarsız kemik grefti önerildi.

\section{Tartışma}

Multipl skleroz çoğunlukla genç yetişkinlerde başlayan MSS'nin birçok bölgesinde inflamasyon, demyelinizasyon ve gliozis alanları ile karakterize kronik bir hastalıktır (8). Hastalığın başlıca semptomları motor, duyusal, görsel, serebellar ve otonomik bozukluklardır $(1,2)$. Rekürren ataklar veya progressif klinik seyir MS için tipiktir. Motor semptomlar tipik olarak güçsüzlük ve spastisite şeklindedir $(3,4)$. Spastisiteye daha çok bacaklarda rastlanır ve ağır spastik parapareziye yol açar. Spastisiteye bağlı sertlik, kramp, spazm ve ağrı olur (5).

MS tedavisi atak tedavisi, profilaktik tedavi ve semptomatik tedavi olarak üçe ayrılabilir. Akut atak, 24 saatten uzun süren, beyaz cevheri etkileyen bir fokal fonksiyon bozukluğudur. Tipik olarak semptomlar saatler ve günler içinde başlar, birkaç

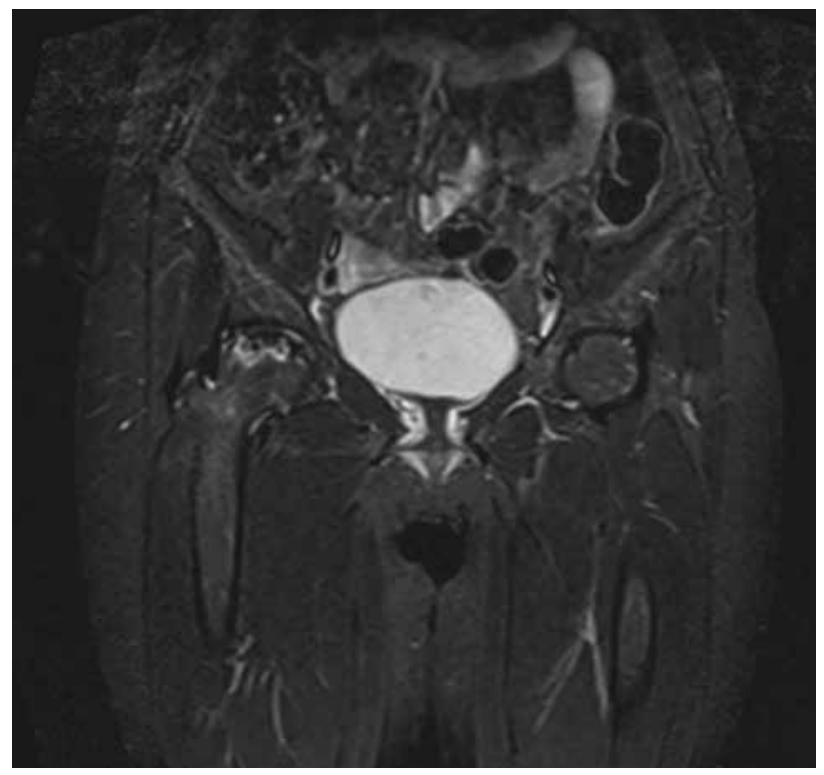

Resim 4. Koronal yağ baskılı T2A MRG görüntüsü. Sağ femur başı subkondral kemik yapıda çökme ve periferi hiperintens santrali hipointens aseptik nekroz alanı izlenmektedir gün boyunca ilerleme gösterir, kısa sürede maksimum seviyeye ulaşır daha sonra günler ve haftalar içinde düzelme beklenir. Bu düzelme kortikosteroid tedavisiyle veya spontan olabilir (9). Akut atak tedavisinde $\mathrm{GC}^{\prime}$ ler ve daha ender olarak adrenokortikotrofik hormon (ACTH) kullanılır. Her iki ilacın antienflamatuvar ve immünsupresif etkileri olup $\mathrm{MS}^{\prime}$ de klinik relaps süresini kısaltırlar. Hastanın klinik durumuna göre karar verilir, her atak tedavi gerektirmeyebilir (10). GC'ler MS tedavisinde sadece ataklar sırasında kullanılır. Ortaya çıkan atağın kısa sürmesi ve tam olarak düzelmesi için yüksek doz GC'ler kullanılmaktadır. Bu tedavi sıklıkla intravenöz pulse metilprednizolon (MP) 1000 mg şeklinde olmaktadır. Uygulamalar arasında farklılıklar olmakla birlikte 3-10 gün boyunca bu tedavi verilir. Tedaviye yanıta veya atağın şiddetine göre bu tedavi izleyen haftalarda tekrarlanabilir. Bazı protokollerde ağızdan alınan GC tedavisi de kullanılmaktadır.

Multipl sklerozun mekanizması tam olarak bilinmemesine rağmen GC'lerin $M S^{\prime}$ in immünolojisinde faydalı etkileri gösterilmiştir (11). Kısa süreli yüksek doz MP tedavisi MS akut ataklarında iyileşme süresini kısaltmaktadır. Başlangıç etkisi hızlıdır, genellikle ilk haftada başlar. Günümüzde kısa süreli yüksek doz MP tedavisinin faydaları kesin kanıtlanmıştır (12). Yüksek doz I.V. veya oral MP tedavisi atakların gerilemesini hızlandırmaktadır. GC'ler MS akut alevlenmesinde sıklıkla kullanılmakla birlikte hala bu ilaçların etkinliği, ilaç tipi, optimal dozu, tedavi süresi, sıklığı, verilme şekli net değildir (13).

GC'lerin MS'de ilk görülen etkisi kan beyin bariyeri bozulmasını önlemektir. Antiödematöz etkisi bir yana bırakıldığında kan beyin bariyeri restorasyonu, steroid hormonların direk ve hızlı membran etkileri ile oluşur (12). GC'ler doz bağımlı etki etmektedirler. T hücre apoptozisi yüksek doz (50 mg/kg gibi) MP sonrası olmakta, fakat düşük dozda (1 mg/kg gibi) görülmemektedir. Bu durum daha çok kan beyin bariyerinin GC'e geçirgenliği ile ilgilidir. Yüksek doz MP (1000 mg/gün) akut dönemde ve takip eden iki ay içinde kontrast tutan lezyon sayısında azalma yapmaktadır. Azalma tedaviden sonraki 30 gün içinde başlar, 60 gün devam eder (14). GC kullanımları sırasında önemli yan etkiler ortaya çıkabilir. Kemilerde osteonekroz gelişebilir. Osteonekroz sinonimleri; avasküler nekroz, iskemik nekroz, subkondral avasküler nekroz, kemiğin avasküler nekrozu, osteokondritis dissekanstır (15). Hastalık en sık kalça eklemini etkilemektedir (16). FBAVN kemiğin kan dolaşımının travmatik veya nontravmatik sorunlar nedeniyle bozulması sonucunda, kemik dokunun canlı hücrelerinin ölümü ile seyreden ve femur başında çökme ve erken eklem dejenerasyonu ile sonuçlanan patolojik bir süreçtir. AVN oluşumunda steroid kullanımı, alkolizm, travma, dolaşım sorunları, orak hücreli anemi ve Gaucher hastalığı en sık etyolojik nedenlerdir. Bazı olgularda etyoloji belli değildir. GC kullanımı nontravmatik osteonekrozun en sık nedenidir (7). Hastalık en sık kalça eklemini etkilemektedir. Sistemik, lokal ve hematolojik faktörler sebep olabilir (17). GC kullanımı embolizasyon, kemik iliği şişmesi, damar duvarı hasarı gibi patogenetik mekenizmalarla AVN oluşturur (7). Kemiğin belirli bir bölgesinde dolaşım bozukluğundan dolayı nekroz 
oluşur. Başlangıçta sağlam olan eklem kıkırdağı, mekanik olarak basınç altında kalmanın da etkisiyle zamanla nekroze olur ve artrit tablosu gelişir (17). FBAVN başlangıç dönemi genellikle semptomsuzdur. Femur başındaki hastalıkı alanın fibröz vasküler doku ile tamirinin başladığı birinci haftadan itibaren hastalarda görülen tek semptom ağrıdır. Ağrı genellikle kasık bölgesinde, nadiren de trokanter üzerinde veya gluteal bölgede hissedilir. Bu aşamada eklem hareketleri korunmuştur. Hastalığın ilerleyen dönemlerinde tamir işlemi, fibröz dokunun ilerlemesi ile devam eder. Oluşan bu dokunun duvarları avaskülerdir ve subkondral kemikte oluşan segmenter çökmenin nedenidir. Bu dönemde hastanın ağrısının belli hareketlerle daha da belirginleştiği ve özellikle iç rotasyonun kısıtlandığı görülür. Hastalığın son dönemlerine kadar eklem kıkırdağı ve asetabulum korunur. Ancak eklem kıkırdağının bozulmasıyla birlikte bir grup hastada, bazı hareketlerde "klik" sesi başlar ki, bunun eklem içi serbest fragman varlığına bağlı olduğu düşünülür. Eklem kıkırdağı ve asetabulumun tutulmasıyla birlikte, ağrının şiddeti belirgin şekilde artar, eklem hareketleri de ileri düzeyde bozulur. Steroide bağlı avasküler nekrozlarda ani ağrı krizleri görülebilir (6).

Manyetik rezonans görüntüleme (MRG), FBAVN tanısında "gold standart" tanı yöntemi olarak kabul edilmektedir. MRG'de, femur başında subartiküler bölgede, dalgalı bir sınırla çevrelenmiş nekrotik bir alan (demarkasyon hattı) izlenir. Bu hat, T2 ağırlıklı görüntülerde, tipik "çift çizgi" (double line sign) bulgusu oluşturur. Dıştaki düşük sinyal intensitesi sklerotik kemiği, içteki yüksek sinyal intensitesi ise vaskülarize granülasyon dokusunu temsil eder (17). Günümüzde kalça osteonekrozu için gözde olan evreleme, modifiye Steinberg sınıflama sistemidir (18).

Bizim olgumuzda, sağ femur başında subartiküler bölgede, dalgalı bir sınırla çevrelenmiş hipointens bir hat izlenmekte olup, T2 ağırlıklı görüntülerde (Resim 4) tipik "çift çizgi" (double line sign) bulgusu izlenmektedir. Burada dıştaki düşük sinyal intensitesi sklerotik kemiği, içteki yüksek sinyal intensitesi ise vaskülarize granülasyon dokusunu temsil eder. Sklerotik alanının içerisindeki kısım nekroz alanını temsil etmekte olup en iyi T1A görüntüde (Resim 2, 3) değerlendirilebilmektedir. Modifiye Steinberg sınıflamasınına göre, bizim olgumuz bu sınıflamaya göre sağ femur başı evre 3 osteonekroz olarak değerlendirildi. Tedavide, hastalığın tanısının konduğu zamandaki evresine göre farklı yöntemler uygulanır (17). Nekrotik süreci engellemek zor olduğundan, FBAVN tedavisi oldukça güç ve sorunludur. Tedavi esnasında hastalığın evresi, etyoloji, semptomların süresi, ağrı, yaş, genel durum, osteonekrozun genişliği, hastalığın unilateral ve bilateral oluşu da belirleyicidir. FBAVN tedavisinde; Nonoperatif tedavi, femur başını koruyucu tedavi ve femur yüzeyinin yenilenmesi şeklinde cerrahi tedavi yöntemleri uygulanır. Nonoperatif tedavi de ağrının ve ekleme binen yükün kanadyen, koltuk değneği veya walker kullanımı ile azaltılması progresyonu yavaşlatmada önemlidir (19). Farmakolojik tedavide osteonekrozun önlenmesi ve tedavisi için onaylanmış herhangi bir ilaç yoktur. Bu hastalığın tedavisi için hastalığın nasıl meydana geldiğini saptamak önemlidir. Osteonekrozda birçok risk faktörü saptanmıştır.
Fakat hastalık başladıktan sonra hangi etkilerin risk faktörlerini azalttığı veya tedavi ettiği bilinmemektedir. Farmakolojik tedavinin etkisini değerlendirmek için yürütülen birçok çalışma mevcuttur. Osteonekroz gelişiminin önlenmesinde bifosfonatlar (20,21), antikoagülanlar (22), lipid düşürücü ajanlar $(23-25)$ ve antihipertansif $(26,27)$ ilaçlarla yapılmış birçok çalışma mevcuttur. Cerrahi tedavi femur başını koruyucu tedavi ve femur yüzeyinin yenilenmesinde şeklinde ikiye ayrilır. Femur başını koruyucu tedavide, core dekompresyon $(28,29)$, elektriksel stimulasyon, intertrokanterik osteotomi, vaskülarize ve nonvaskülarize kemik greftleri uygulanır. Elektriksel stimülasyon, intertrokanterik osteotomi ve vaskülarize ve non vaskülarize kemik greftleri uygulanır. Elektriksel stimülasyon tedavisi: Primer tedavi olarak ya da kor dekompresyon veya kemik greft uygulamasına ek tedavi olarak uygulanır (19). Femur yüzeyinin yenilenmesinde; yüzey replasman artroplasti, hemiartroplasti, total kalça artroplasti yapılır $(18,30,31)$. Biz olgumuzun tedavisinde analjezik ilaç olarak zayıf opioid, koltuk değneği, spastisite için her iki diz, kalça ve ayak bileğine soğuk paket verildi. Her iki alt ekstremitelere progresif dirençli kas güçlendirici egzersizler, germe egzersizleri, sağ kalçaya TENS, denge, yürüme ve koordinasyon eğitiminden oluşan fizik tedavi ve rehabilitasyon programı uygulamayı tercih ettik. Tedavi sonucunda olgunun ağrı VAS'ı 8 cm'den 4 cm'ye geriledi, spastisite azaldı. Ortopedi kliniği ile konsülte edildi ve hasta semptomatik ve MRG'nin pozitif olduğu çökme öncesi dönemde olduğundan; kor dekompresyon ve damarlı veya damarsız kemik grefti önerildi.

\section{Sonuç}

MS'li hastaların rehabilitasyon öncesinde anamnez detaylı alınmalı. Atak geçirme durumu ve GC kullanma öyküsü sorgulanmalı. GC kullanma öyküsü varsa AVN mutlaka ekarte edilmeli. Kalça hareketleri ağrıı ve kısıtı MS hastalarında kısıtlıık yalnız spastisiteye bağlanmamalı ve FBAVN ayırıcı tanıda yer almalıdır. MS'li hastalarda FBAVN'nin erken teşhis ve tedavisi ile ileri deformitelerin önlenenebileceği kanaatindeyiz.

\section{Kaynaklar}

1. Ropper AH, Brown RH. Adams and Victor's Principles of Neurology, 8th ed. New York, McGraw-Hill, 2005:36:771-2.

2. Feinstein A. The Neuropsychiatry of Multiple Sclerosis. Can J Psychiatry 2004;49:157-63.

3. Compston A, Coles A. Multiple sclerosis. Lancet 2002;359:1221-31.

4. Fox RJ, Bethoux F, Goldman MD, Cohen JA. Multiple sclerosis: advances in understanding, diagnosing, and treating the underlying disease. Cleve Clin J Med 2006;73:91-102.

5. Idiman E. Demiyelinizan hastalıklar. In: Oğul E (ed). Klinik Nöroloji, İstanbul, Nobel-Güneş Yayınevi, 2002:159-85.

6. Ege R. Femur başı avaskuler nekrozu. In: Ege R (ed). Kalça cerrahisi ve sorunları, Ankara, Türk Hava Kurumu Basımevi, 1996:752-67.

7. Kerachian MA, Séguin C, Harvey EJ. Glucocorticoids in osteonecrosis of the femoral head: a new understanding of the mechanisms of action. J Steroid Biochem Mol Biol 2009;114:121-8.

8. Rowland LP. Merritt's neurology, 10th ed. Philadelphia, Lippincott Williams \& Wilkins, 1999:121.

9. Keegan BM, Noseworthy JH. Multiple sclerosis. Annu Rev Med 2002:53:285-302.

10. Miller AE, Lublin FD, Coyle PK. Multiple Sclerosis in Clinical Practice, London, Martin Dunitz Press, 2003:5. 
11. Kinkel RP. Methylprednisolone. In: Rudick RA, Goodkin DE. Multipl sclerosis therapeutics, London, Martin Dunitz Press, 1999:12.

12. Filipovic SR, Drulovic J, Stojsavljevic N, Levic Z. The Effects of highdose intravenous methylprednisolone on event-related potentials in patients with multiple sclerosis. J Neurol Sci 1997;152:147-53.

13. Filippini G, Brusaferri F, Sibley WA, Citterio A, Ciucci G, Midgard R, et al. Corticosteroids or ACTH for acute exacerbations in multiple sclerosis. Cochrane Database Syst Rev 2000;CD001331.

14. Pozzilli C, Marinelli F, Romano S, Bagnato F. Corticosteroids treatment. J Neurol Sci 2004;223:47-51.

15. Jacobs B. Epidemiology of traumatic and non traumatic osteonecrosis. Clin Orthop Rel Res 1978;130:51-7.

16. Watson RM, Roach NA, Dalinka MK. Avascular necrosis and bone marrow edema syndrome. Radiol Clin N Am 2004;42:207-19.

17. Duda SH, Laniado M, Schick F, Claussen CD. The doubleline sign of osteonecrosis: evaluation on chemical shift MR images. Eur J Radiol 1993;16:233-8.

18. Rizzo M, Urbaniak JR. Osteonecrosis. In: Harris ED, Budd RC, Firestein GS, Genovese MC, Sergeant JS, Ruddy's Sledge CB (eds) Kelley's Textbook of Rheumatology, 7th ed. Philadelphia, Elsevier Saunders, 2005:1812-28.

19. Petrigliano FA, Lieberman JR. Osteonecrosis of the hip: novel approaches to evaluation and treatment. Clin Orthop Relat Res 2007; 465:53-62.

20. Lai KA, Shen WJ, Yang CY, Shao CJ, Hsu JT, Lin RM. The use of alendronate to prevent early collapse of the femoral head in patients with nontraumatic osteonecrosis. A randomized clinical study. J Bone Joint Surg Am 2005;87:2155-9.

21. Little DG, McDonald M, Sharpe IT, Peat R, Williams P, McEwoy T Zoledronic acid improves femoral head sphericity in a rat model of perthes disease. J Orthop Res 2005;23:862-8.

22. Glueck CJ, Freiberg RA, Sieve L, Wang P. Enoxaparin prevents progression of stages I and II osteonecrosis of the hip. Clin Orthop Relat Res 2005;435:164-70.

23. Nishida K, Yamamoto T, Motomura G, Jingushi S, Iwamoto $Y$. Pitavastatin may reduce risk of steroid-induced osteonecrosis in rabbits: a preliminary histological study. Clin Orthop Relat Res 2008:466:1054-8

24. Iwakiri K, Oda Y, Kaneshiro Y, Iwaki H, Masada T, Kobayashi, A et al. Effect of simvastatin on steroid-induced osteonecrosis evidenced by the serum lipid level and hepatic cytochrome P4503A in a rabbit model. J Orthop Sci 2008;13:463-8.

25. Pritchett JW. Statin therapy decreases the risk of osteonecrosis in patients receiving steroids. Clin Orthop Relat Res 2001;386:173-8.

26. Disch AC, Matziolis G, Perka C. The management of necrosisassociated and idiopathic bone-marrow oedema of the proximal femur by intravenous iloprost. J Bone Joint Surg Br 2005;87:560-

27. Laroche $M$, Jacquemier JM, Montane de la Roque $P$, Arlet J, Mazières B. Nifedipine per os relieved the pain caused by osteonecrosis of the femur head. Rev Rhum Mal Osteoartic 1990;57:669-70.

28. Lieberman JR, Conduah A, Urist MR. Treatment of osteonecrosis of the femoral head with core decompression and human bone morphogenetic protein. Clin Orthop Relat Res 2004;429:139-45.

29. Wang CJ, Wang FS, Huang CC, Yang KD, Weng LH, Huang HY. Treatment for osteonecrosis of the femoral head: comparison of extracorporeal shock waves with core decompression and bonegrafting. J Bone Joint Surg Am 2005;87:2380-7.

30. Stulberg BN. Osteonecrosis: What to do, What to do!. J Arthroplasty 2003;18:74-9.

31. Mazieres B. Osteonecrosis. In: Hochberg M, Silman AJ, Smolen J, Weinblett ME, Weisman MH (eds). Rheumatology, 3rd ed. Edinburgh, Mosby, 2003:1877-90. 